\title{
Trabajadores pobres y empobrecimiento en España
}

\section{Jorge Aragón}

Fundación $1^{\circ}$ de Mayo

<jaragon@1mayo.ccoo.es>

\section{Jesús Cruces}

Fundación $1^{\circ}$ de Mayo

\section{Luis de la Fuente}

Fundación $1^{\circ}$ de Mayo

\section{Alicia Martínez}

Fundación $1^{\circ}$ de Mayo

\section{Amaia Otaegui}

Fundación $1^{\circ}$ de Mayo
Langile pobreak egoteak haustarazten ditu enpleguan oinarri hartutako Estatu Sozialaren oinarrizko premisak. Enpleguak ez du babesik eskaintzen pobreziari aurre hartzeko, eta ongizate Estatuen desegiteak haztarazten ditu desberdintasun-maila eta justiza eza. Espainian ezarritako ekonomia eta laneko hazkunderako ereduak eratu ditu enplegua txikitu eta laneko ezegonkortasunaren oinarriak. Ongizate Estatu ahula indartzeko borondate politiko eskasak eta bizkortu izandako erreforma eta murrizketa sozialek kondenatzen dute biztanleriaren zati nabarmen bat, eta zailtasunak izango dituzte pertsona horiek eskubide sozialak jaso eta premia materialak asetzeko. Gero eta desberdintasun-maila handiagoa eta elkartasun gutxiago ezagutuko du gure gizarteak; suspertze ekonomiko eta soziala urrunago egongo da, eta zailagoa izango da gizarte aske eta demokratikoagoa sortzen.

\section{HITZ-GAKOAK:}

langile pobreak, krisia, desberdintasuna, produkziosistema, laneko merkatua.
La existencia de trabajadores pobres rompe con una de las premisas básicas de los Estados sociales basados en el empleo. Éste ha dejado de ser una salvaguarda contra la pobreza y el desmantelamiento de los Estados de bienestar está provocando un aumento de la desigualdad e injusticia social. El modelo de crecimiento económico y laboral español ha configurado las bases para una fuerte destrucción de empleo y una alta precariedad laboral. La falta de voluntad política por reforzar el débil Estado de bienestar, unida al acelerado ritmo de reformas y recortes sociales, condenan a gran parte de la población a sufrir serias dificultades para acceder a derechos sociales y cubrir necesidades materiales básicas. El desigual reparto de la crisis aboca a una sociedad cada vez más desigual e insolidaria, que se aleja tanto de las posibilidades de una recuperación económica y social sostenible, como de la construcción de una sociedad más libre y más democrática.

\section{Palabras Clave:}

trabajadores pobres, crisis, desigualdad, sistema productivo, mercado de trabajo. 


\section{Introducción}

El fenómeno de los trabajadores pobres es estructural en determinadas sociedades donde las precarias condiciones de empleo y de salario se unen a la escasez de recursos sociales. En los Estados sociales europeos, la magnitud de los trabajadores empobrecidos se está extendiendo, consecuencia de la grave crisis económica de los últimos años y de los fuertes recortes sociales. En un contexto de pobreza creciente, el acceso al empleo ya no es una salvaguarda ante las situaciones de pobreza. La precarización de las condiciones de trabajo, los procesos de desprotección en el mercado de trabajo y el debilitamiento de los recursos sociales del Estado de bienestar están provocando un empobrecimiento generalizado que ya alcanza a la población trabajadora.

La misma existencia de trabajadores pobres rompe con la idea de que la integración en el mercado laboral es la condición básica para evitar la pobreza, la exclusión social o la privación material: porque aunque los salarios son un elemento crucial, la pobreza va más allá; porque la pobreza se materializa en los hogares; y porque las políticas públicas tienen un papel fundamental en la redistribución de la riqueza y la reducción de la desigualdad.

En los últimos años de la crisis económica, el empobrecimiento de la población no sólo ha quedado plasmado en el incremento generalizado de las tasas de riesgo de pobreza, y de la pobreza y exclusión social, así como de trabajadores pobres, sino en la propia evolución de la frontera entre la pobreza y la no pobreza. La tendencia a la reducción de la cuantía del umbral de la pobreza tiene un alcance determinante a la hora de hablar de la pobreza, su impacto, su gravedad y su irreversibilidad: en la coyuntura actual, una disminución del umbral de la pobreza supone, por un lado, no considerar pobres a personas que, con un mismo nivel de ingresos, lo eran antes; $y$, por otro, que quienes son considerados pobres, son aún más pobres.

El presente artículo aborda la situación de los trabajadores pobres y el empobrecimiento progresivo de la población española a lo largo de los últimos años, a partir de los diversos factores que inciden en este fenómeno, así como del impacto que están teniendo las políticas de recortes -en el ámbito laboral, sanitario, educativo y de la dependencia- en las condiciones de vida actuales (y futuras) de la población.

\section{2. ¿Quienes son los trabajadores pobres?}

El concepto de trabajadores pobres es complejo, ya que integra tres perspectivas: individual, ligada a las condiciones de trabajo; de los hogares, relacionada con los contextos de convivencia de los trabajadores; así como con los niveles de renta (rentas salariales y otros recursos). Los trabajadores pobres, llamados en la Unión Europea y en la amplia literatura anglosajona woorking poor o in-work poverty son individuos ocupa- dos -tanto asalariados como trabajadores por cuenta propia-durante al menos siete meses en el año previo a la encuesta, y que pertenecen a hogares cuya renta anual disponible se encuentra por debajo del umbral de la pobreza. Este umbral se corresponde con el $60 \%$ del ingreso neto anual familiar mediano de cada país. Igualmente, la renta de los hogares se compone de diferentes conceptos, dentro de los cuales se encuentran las transferencias sociales.

En el caso de España, esta definición convencional presenta varias limitaciones que conviene resaltar. En primer lugar, hay que destacar que la precariedad y temporalidad en el mercado de trabajo español desborda esta definición: el límite que se establece entre la persona ocupada y persona que no lo está responde de alguna manera a una concepción conservadora de un mercado de trabajo dual. El segmentado mercado de trabajo español sobrepasa esta perspectiva, ya que presenta diferentes perfiles con trayectorias diversas de entrada y salida del empleo, de participación en la economía sumergida, así como de actividades reproductivas al margen de lo que se considera ocupación laboral, especialmente en los últimos años de crisis económica.

En segundo lugar, es necesario precisar que no se tiene en cuenta el acceso a recursos básicos. Esta forma de medir la pobreza considera el riesgo de exclusión social en función de la desigualdad de ingresos, y no del acceso a los recursos básicos para satisfacer las necesidades humanas; una perspectiva más adaptada a las realidades de los países más empobrecidos. Y finalmente, también hay que cuestionar esta definición en tanto en que dentro de los hogares no se tiene por qué compartir ingresos por igual. Se obvia, por lo tanto, la diversidad de unidades de convivencia y el reparto desigual de las diferentes fuentes de la renta de los hogares.

\section{La evolución de la pobreza de los trabajadores en España}

En los últimos años, el elemento clave para comprender el alcance de la evolución de la pobreza, tanto general como particular de los trabajadores, es la evolución del umbral de riesgo de pobreza; es decir, el límite económico que separa a quienes son considerados pobres de quienes no. Tal como se puede apreciar en el Gráfico 1, desde el año 2009 la cuantía que determina la frontera de la pobreza no ha dejado de descender. Esta evolución implica dos tendencias fundamentales: el descenso generalizado de los ingresos, así como el agravamiento de las condiciones de vida de quienes son considerados pobres. Mientras en el año 2009 eran pobres las personas que vivían con menos de 7.980 euros anuales, en 2012 son pobres los que no alcanzan los 7.355, es decir, 625 euros menos.

En este contexto de empobrecimiento generalizado, y pese a la disminución del umbral, el porcentaje de 


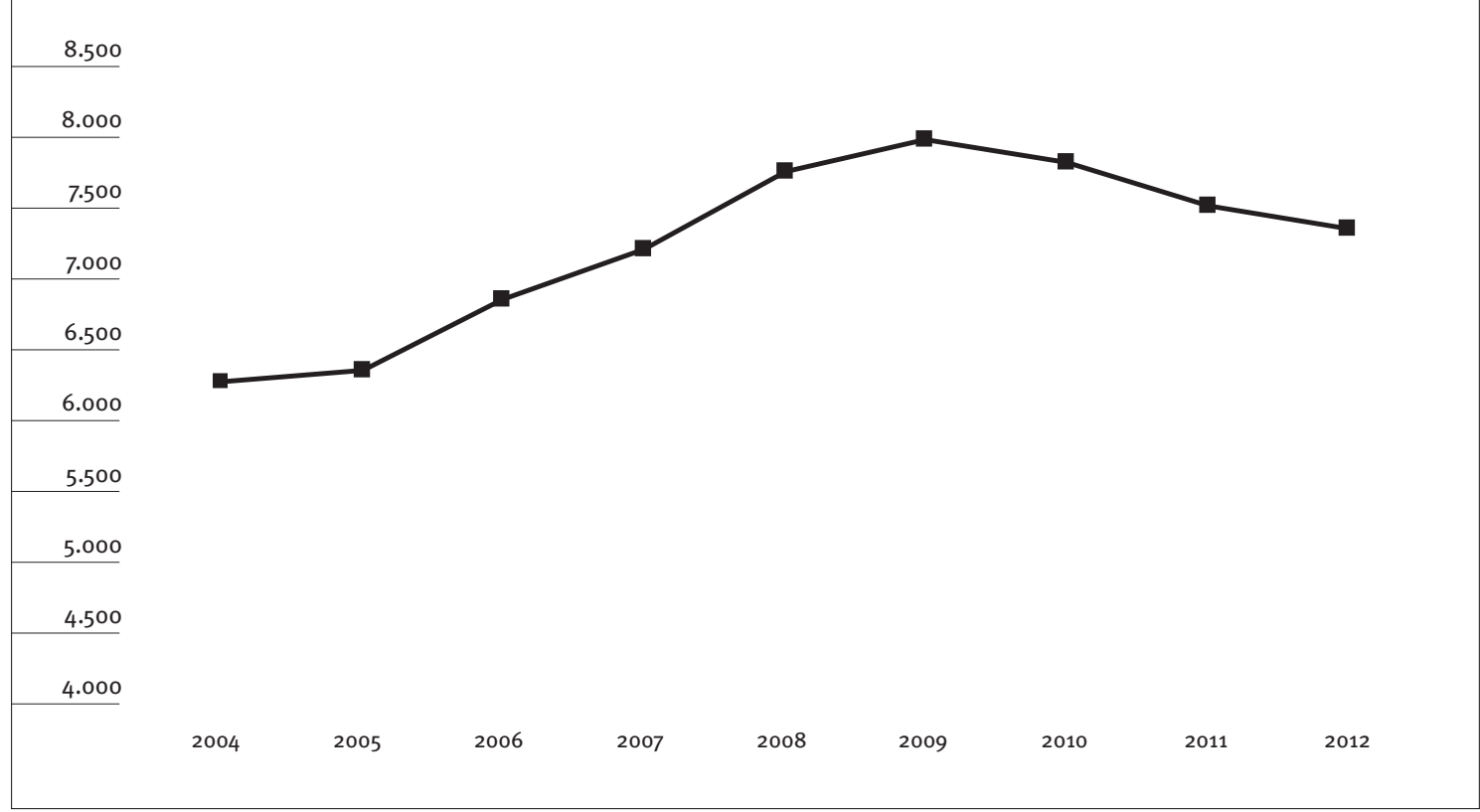

Fuente: Elaboración propia a partir de la Encuesta de Condiciones de Vida 2012 (INE).

trabajadores y trabajadoras en riesgo de pobreza en España ha pasado del 10,4\% en 2005 al 12,7\% en el año 2010, una tasa que muestra una tendencia opuesta a la media europea y llega a ser 4,3 puntos superior. Los datos provisionales de 2011 de la Encuesta de Condiciones de Vida arrojan una ligera disminución de la tasa, condicionada principalmente por la importante reducción de la frontera de la pobreza. De esta manera, el tibio descenso de las tasas provisionales de la pobreza de los años 2011 y 2012 no esconden sino una degradación de las condiciones de vida de una parte importante de la población y de los trabajadores.

\section{4. ¿Qué factores influyen en la pobreza de los trabajadores y trabajadoras?}

A la hora de analizar el fenómeno de los trabajadores pobres, es necesario considerar distintos elementos, que explican la heterogénea y diversa realidad de situaciones de pobreza. Así, se pueden distinguir cuatro grandes grupos de factores:
- Factores laborales, condicionados por el modelo productivo y las pautas de crecimiento de las últimas décadas.

- Perfiles sociales, asociados a las diferentes posiciones de las personas en un mercado de trabajo segmentado, incluso atomizado, como el español.

- Circunstancias de los hogares, que determinan el reparto de los ingresos, especialmente afectado por el cada vez más extenso desempleo.

- Transferencias y derechos sociales, que constituyen el marco de acceso a los recursos básicos para la salvaguarda de las condiciones de calidad de vida y el reparto social de la renta y la riqueza.

Estos factores dibujan situaciones laborales, personales y sociales de mayor o menor precariedad, que son determinantes en el conjunto de países de la Unión Europea. Sin embargo, su incidencia en cada país es bien distinta. Durante el periodo de crisis, el crecimiento del desempleo está teniendo un impacto decisivo en el aumento de los trabajadores pobres en

\begin{tabular}{|l|l|l|l|}
\hline \multicolumn{2}{|l|}{ Cuadro 1. Factores condicionantes de la pobreza } \\
\hline Laborales & Sociales & Hogares & Transferencias y derechos sociales \\
\hline $\begin{array}{l}\text { - Situación profesional } \\
\text { - Tipo de contrato }\end{array}$ & $\begin{array}{l}\text { - Sexo } \\
\text { - Edad } \\
\text { - Nivel educativo } \\
\text { - Bajos salarios y salario } \\
\text { mínimo interprofesional }\end{array}$ & $\begin{array}{l}\text { - Intensidad laboral } \\
\text { - No de cohabitidantes econó- } \\
\text { micamente dependientes }\end{array}$ & $\begin{array}{l}\text { - Servicios sociales } \\
\text { - Transferencias sociales } \\
\text { - Marco de derechos laborales }\end{array}$ \\
& & \\
\hline
\end{tabular}

Fuente: Elaboración propia. 
todos los países europeos. Pero más allá del aumento del paro, hay que considerar otros aspectos, como los recortes salariales, la reducción del tiempo de trabajo o la disminución de las prestaciones sociales, que se están produciendo en distintos países de la Unión Europea (Eurofound, 2010). La existencia de bajos salarios y empleo sumergido son elementos comunes que favorecen el aumento de los trabajadores pobres en todos los países europeos, pero existen factores -como una menor participación laboral y los costes familiares por hijo-que tienen un mayor peso en unos países que en otros (Goerne, 2011).

Las diferencias entre el riesgo de pobreza de los trabajadores españoles y de la mayoría de países europeos se explican principalmente, por un lado, por la debilidad y precariedad del mercado de trabajo español configurado durante la época de crecimiento, que generó un gran volumen de empleo sujeto a condiciones más vulnerables; y por otro, por la debilidad del Estado de bienestar y su capacidad redistributiva, que no ha permitido reducir los niveles de desigualdad durante el periodo de crecimiento económico de los últimos años (Rodríguez Cabrero, 2010; García-Espejo y Gutiérrez, 2011).

\section{El modelo de crecimiento y de empleo de las últimas décadas}

El sistema productivo español propició una prolongada fase de expansión desde mediados de los años noventa hasta 2007 que, sin embargo, tenía importantes debilidades. Se trató de un crecimiento heterogéneo, asentado en actividades de escaso valor añadido y con mucha intensidad de mano de obra, que fue capaz de generar un gran volumen de empleo, pero también con elevados niveles de precariedad. Se configuró un mercado de trabajo muy segmentado y sustentado, en una gran parte, en patrones laborales basados en la creación de empleo irregular, temporal, de baja cualificación y con bajos salarios (Rocha, Aragón y Cruces, 2008).

El crecimiento ha sido, sin embargo, desigual, hecho que se manifiesta en que, aunque España crecía por encima de la media europea, las tasas de pobreza tan sólo se redujeron ligeramente (del $24 \%$ al $23 \%$ entre 2004 y 2007, según los datos de Eurostat). Esta variación producida tras años de fuerte crecimiento económico no ha conseguido mitigar la distancia existente respecto a la Unión Europea. Tan sólo se consiguió una reducción limitada de la desigualdad; así, los ingresos de las personas con mayor renta pasaron de representar de 6 veces a 5 veces los ingresos de las personas con menos renta. Esta tendencia también se puede observar en la evolución del coeficiente de Gini -donde o significa la igualdad de rentas y 100 la máxima desigualdad-, que descendió desde 34 puntos en 1995 a 31 en $2007^{2}$.

${ }^{2}$ Fuente: Eurostat, 2012.
No obstante, se produce en este periodo una cierta mejora en los indicadores relacionados con la pobreza: la tasa de pobreza y exclusión social se redujo un punto, la tasa de paro en 3 puntos, la tasa de cobertura de las prestaciones creció un 10\%, el salario mediano se incrementó un $14 \%$ y el salario mínimo interprofesional lo hizo en un $24 \% 3$. Una tendencia moderada si se compara con la evolución general de la economía.

También hay que mencionar que el crecimiento económico registrado en este periodo no se aprovechó para reforzar el Estado del bienestar. Así, entre 2004 y 2007, el gasto público en protección social crecía a un ritmo muy débil (del 20,3\% al 20,7\% del $\mathrm{PIB})$, mientras que el gasto público en educación se mantuvo estancado ( $4,3 \%$ del PIB).

La conjugación del sobreendeudamiento familiar y el abaratamiento del crédito bancario, acompañado de un gran número de empleos marcados por la precariedad, los bajos salarios y la creciente desprotección social, explica también la mayor incidencia de los impactos de la crisis desde 2009 , que ha propiciado que la tendencia de reducción de la desigualdad experimentada durante la fase de expansión se transformara durante el periodo de crisis en un rápido aumento de la desigualdad (alcanzando un coeficiente de Gini de 34 puntos en 2010), mientras que la renta de las personas que más ingresos declaraban suponía casi 7 veces la de aquellos que tenían menos recursos.

Con la crisis económica, las situaciones de pobreza empiezan a empeorar desde el año 2008 y la situación se agudiza a partir de 2010. La tasa de pobreza y exclusión social aumenta más de dos puntos porcentuales entre 2008 y 2010 , mientras que la tasa de paro casi se duplica hasta alcanzar el $20 \%{ }^{4}$; el número de familias con todos sus miembros activos en paro aumenta -hasta los 1,7 millones-, ampliándose de esta forma las situaciones de hogares en situaciones de privación material ${ }^{5}$.

\section{Trabajadores pobres: perfiles laborales y sociales}

El empobrecimiento de los trabajadores no es homogéneo. El trabajo por cuenta propia, la temporalidad, la inestabilidad y la parcialidad son condiciones laborales que se encuentran asociadas a mayor nivel de riesgo de pobreza. Por lo otro lado, también son claves las circunstancias de los entornos familiares, como la intensidad de empleo en el hogar ${ }^{6}$, que se

\footnotetext{
3 Fuente: Encuesta de Condiciones de Vida y Encuesta de Población Activa (INE) y Ministerio de Empleo y Seguridad Social, 2012.

4 Una tendencia que se agrava hasta superar el $25 \%$ en el tercer trimestre de 2012 (EPA, INE).

${ }^{5}$ Fuente: Encuesta de Condiciones de Vida y Encuesta de Población Activa, 2012 (INE).

${ }^{6}$ La intensidad laboral de los hogares mide el porcentaje de sus integrantes en edad laboral -a excepción de los estudiantes- que
} se encuentran ocupados, siendo o\% si no trabaja ningún integrante 
ha visto reducida gravemente en estos últimos años, debido a la elevadísima destrucción de empleo.

En función de los distintos factores que intervienen en la pobreza de la población trabajadora, se puede identificar varios perfiles sociolaborales. Así, de acuerdo con los datos de la Encuesta de Condiciones de Vida (2012) se observa que:

- El trabajo por cuenta propia tiene un elevado riesgo en España: el 40\% de los trabajadores por cuenta propia se encontraban en riesgo de pobreza, frente al 7,1\% de los trabajadores por cuenta ajena.

- La temporalidad de la contratación implica un mayor grado de vulnerabilidad, una característica reseñable del mercado de trabajo que se generó durante la época de crecimiento económico. Pese a haberse reducido la temporalidad considerablemente, fruto de la fuerte destrucción de este tipo de empleos, ésta sigue siendo un aspecto diferenciador del mercado de trabajo español. Así, el $25 \%$ de los asalariados tenían un contrato temporal en el año 2011. El 13,5\% de estos trabajadores temporales vivía por debajo del umbral de riesgo de pobreza.

- El trabajo a tiempo parcial muestra mayores tasas de pobreza. Si bien es cierto que las tasas de empleo a tiempo parcial son considerablemente inferiores en España respecto a la media europea -incluso tras su ascenso en el periodo de crisis-, es importante considerar que este tipo de empleo está asociado a peores condiciones salariales y de protección social en el caso español. La tasa de pobreza de empleo a tiempo parcial era, en 2011, de un $18,5 \%$, no sólo superior a la media española, sino 6 puntos superior a la media europea. Esta cifra no sólo alerta sobre la precariedad de este tipo de empleos en España, sino que explica la desmesurada involuntariedad asociada a él y sus implicaciones en la calidad de vida de las mujeres, que lo ocupan mayoritariamente.

- La edad es un elemento diferenciador en los perfiles de riesgo de pobreza, como también lo es en la situación en el mercado de trabajo: son de sobra conocidas las altísimas tasas de desempleo de los jóvenes y las dificultades de reincorporación al mercado de trabajo de los mayores de 55 años. La tasa de pobreza de la población joven (de 16 a 29 años) fue del $11,2 \%$, considerablemente inferior a la tasa del año anterior. Este fenómeno puede explicarse por el proceso de reunificación de los hogares familiares, que se une a la ya de por sí tardía emancipación de los jóvenes. De esta manera, la precaria situación de los jóvenes se ve diluida en los contextos familiares. Por otro lado, la tasa de la población trabajadora de 55 y 64 años es superior a la media (13,3\%).

del hogar y $100 \%$ si están todos ocupados. Se consideran hogares de baja intensidad laboral aquellos con una intensidad entre el $0,2 \%$ y el $45 \%$, y de alta intensidad laboral a aquellos entre $85 \%$ y $100 \%$.
- El empleo de las mujeres mitiga las situaciones de pobreza de las familias, ya que el $11 \%$ de las mujeres que trabajan se encuentran en hogares en riesgo de pobreza, frente al $14 \%$ de los varones.

- Los trabajadores con bajo nivel formativo registraron una tasa de pobreza de $19,5 \%$, mientras que aquellos con formación superior alcanzaron una tasa del 6,2\%. Este dato es especialmente relevante en España, dados los preocupantes datos de abandono escolar temprano, que superaba el $30 \%$ en el periodo de crecimiento económico y que, aunque se ha mitigado suavemente en los últimos años, se mantiene muy por encima de la media europea.

- El 34,3\% de los trabajadores de hogares con baja intensidad de empleo estaban en riesgo de pobreza. No se puede obviar, a este respecto, que los últimos datos arrojan que existen 1,7 millones de familias con todos sus miembros en situación de desempleo, un dato que crece velozmente.

- El $21,9 \%$ de los trabajadores con hijos a cargo viven por debajo del umbral de la pobreza.

En todos estos perfiles sociales de la población trabajadora, la tasa de pobreza de 2011 se reduce con respecto al año anterior, salvo los trabajadores temporales y a tiempo parcial (que aumentan cada uno 5 décimas), los que tienen una formación superior (2 décimas) y los trabajadores que se encuentran en hogares con baja intensidad del empleo (9 décimas).

El escenario de recrudecimiento progresivo de la crisis, de descenso de las rentas de los hogares y de aumento del paro (Fundación de las Cajas de Ahorros, 2012) induce a esperar que se produzca una continuación del empobrecimiento general de la población. A partir de la evolución de incremento de la tasa del paro en el año 2011 y de congelación del salario mínimo interprofesional en el año 2012, se prevé un agravamiento de la pobreza y la exclusión social en España, hasta alcanzar una cifra cercana al $28 \%$ a finales del 2012 y superior en los años siguientes. Estas cifras pueden incluso ser mayores si se considera el impacto de las reformas estructurales -eufemismo de recortes- en servicios públicos básicos, como la educación, la sanidad o la atención a la dependencia en los hogares (VV.AA., 2012).

\section{Recortes de derechos laborales y sociales}

Las políticas de austeridad y recortes sociales están suponiendo un empeoramiento significativo de las condiciones laborales y de vida de la población. Así, en la línea de las últimas reformas (Ley 35/2010, Real Decreto-ley 7/2011), la reforma laboral decretada en febrero de 2012 (Real Decreto-ley 3/2012) ha supuesto un fuerte recorte de derechos laborales y sociales. Lejos de solucionar las debilidades del mercado laboral, la reforma dificulta el acceso al empleo y aumenta la segmentación del mercado de trabajo, abaratando el despido y otorgando al empresario un 
poder prevalente sobre las condiciones laborales de los trabajadores en materias básicas, como el salario. Esta reforma supone una limitación al derecho a la negociación colectiva y favorece el decaimiento de los convenios colectivos al limitar la ultraactividad de los convenios, que, previsiblemente, va a generar una mayor segmentación del mercado de trabajo y de las condiciones laborales.

Por otro lado, las políticas sociales (de protección al desempleo, sanidad, educación, servicios sociales o dependencia) han visto mermados sus recursos como consecuencia de las políticas económicas de austeridad emprendidas durante la fase de crisis. Esta merma en los recursos, junto con una mayor necesidad de protección por parte de la población, está provocando una notable reducción de calidad en los servicios prestados y a una merma de la capacidad protectora del Estado. Lo cual deja en una difícil situación al ya de por sí débil desarrollo del Estado de bienestar en España, que se sitúa muy por debajo del resto de países de la Unión Europea7.

Se trata, además, de medidas orientadas a reducir la capacidad de intervención del Estado como garante de la protección: se argumenta una supuesta falta de eficiencia del sector público para realizar un cambio de modelo de 'protección' en el que el sector privado vaya adquiriendo un mayor peso en la prestación de servicios públicos. Con este tipo de reformas se están sentando las bases de una mayor segmentación de la protección social que desembocará en un modelo asistencial, en el que la cobertura por parte del Estado se centrará en los sectores más vulnerables de la población, dejando al mercado la protección de las clases sociales con recursos económicos.

La reforma del sistema educativo (Real Decreto-ley 14/2012) incorpora una serie de cambios sustanciales que dificultan el acceso universal a la educación pública y las condiciones laborales de sus profesionales, promoviendo de modo paralelo una merma en la calidad educativa pública.

Concretamente, con respecto a las enseñanzas no universitarias, las medidas de reforma del sistema educativo tienen como resultado inmediato un significativo aumento de la ratio del alumnado por docente, así como de las horas lectivas del profesorado. A corto plazo, también suponen un retraso en la implantación de la enseñanza de formación profesional, ya de por sí debilitada, y la delimitación de la escolarización obligatoria a los términos estrictamente legales, lo que implica que, por ejemplo, la educación infantil quede fuera de la enseñanza

7 El gasto social en España a lo largo de la última década ha oscilado entre el $20 \%$ y $21 \%$ del PIB, según los datos de Eurostat. Esta evolución no se ha correspondido con el crecimiento económico experimentado a lo largo de las últimas décadas, ya que la riqueza generada no se tradujo en un incremento del gasto social en la misma medida (Sánchez Llopis, 2010). Además, este dato es un claro indicador del débil desarrollo y financiación del Estado de bienestar en España, que ha venido registrando un gasto considerablemente inferior a la media europea (en torno a 5 puntos porcentuales). pública y deba ser cubierta por el mercado o atendida en el ámbito del hogar. De la misma forma, estas medidas incluyen la supresión de las ayudas ligadas a la educación (como becas de comedor y material escolar), que deben ser asumidas por las familias, lo cual, en un contexto de incremento de la pobreza, es un elemento de especial relevancia, ya que pueden derivar en situaciones de malnutrición infantil.

Dentro de las enseñanzas universitarias, las políticas de reformas están suponiendo un cambio cualitativo del modelo existente hasta la fecha. Así, con la premisa de la necesidad de reducción del déficit, el Gobierno se arroga la potestad de determinar los requisitos básicos para la creación o mantenimiento de los centros y estructuras universitarias, lo cual rompe con el principio de autonomía universitaria y abre el camino a la priorización de los criterios económicos (como único criterio de valoración) para el desarrollo de las actividades universitarias.

La reducción de los fondos públicos y la apertura a la financiación privada (desde proyectos, consorcios o acuerdos) es un claro indicativo del modelo de universidad que se está definiendo, orientada hacia la iniciativa privada y alejada de los campos de la enseñanza y la investigación, socialmente relevantes para las necesidades presentes y futuras del país. Dentro de esta lógica, en el ámbito universitario se ha producido un significativo incremento de las tasas universitarias, tanto en los estudios de grado como de masters. También se han suprimido diversas ayudas y becas al estudio, que hacen imposible el acceso a la educación universitaria de muchos jóvenes y que suponen un fuerte esfuerzo económico para las familias.

Por su parte, las últimas reformas emprendidas en sanidad (Real Decreto-ley 16/2012) están dificultando el acceso de la población a servicios sanitarios públicos básicos, a la vez que abren la posibilidad de que éstos sean satisfechos mediante fórmulas privadas, lo que fomenta el empobrecimiento de determinados segmentos de población con menores rentas e ingresos. Estos recortes suponen el fin del modelo de atención sanitaria universal, vinculando la prestación con el aseguramiento y la situación laboral, excluyendo así del sistema público a aquellas personas que no gozan de la condición de asegurado.

Así, entre otros cambios, se amplían las prestaciones sanitarias que dejan de estar cubiertas en su totalidad por el Sistema Nacional de Salud (SNS). Se separan los servicios del SNS en tres modalidades: básica, suplementaria y accesoria. Mientras que la primera se identifica como gratuita, las otras dos siguen normas de copago. Se ven especialmente afectados los enfermos crónicos y las rentas más bajas, para quienes podría ser inaccesible cubrir sus necesidades sanitarias. Igualmente, las personas inmigrantes en situación irregular pierden su condición de asegurado y se dificulta su acceso al sistema a menos que suscriban un seguro médico privado o un convenio con el país de origen. Ésta es una medida claramente discrimi- 
natoria, cuya implantación repercute negativamente a las arcas de la Seguridad Social y representa serios problemas para el conjunto de la población en el ámbito de la salud pública (en términos de prevención y control de enfermedades).

En el ámbito farmacéutico, un número importante de fármacos dejan de estar cubiertos por el Sistema Nacional de Salud y deben ser pagados por la ciudadanía. Asimismo, se establece un porcentaje mayor de la contribución de la gran parte de los ciudadanos en el precio de venta al público (que pasa del $40 \%$ al $50 \%$ ). Los pensionistas dejan de estar exentos del pago farmacéutico y aquellos con rentas inferiores a 100.000 euros pasan a contribuir con un $10 \%$ del precio de venta al público. Con ello, disminuirá drásticamente los recursos que estas personas aportan a la unidad de convivencia, especialmente en aquellas que ya viven en una situación de pobreza, lo que, a buen seguro, incidirá en su salud.

Se trata de un cambio de modelo sanitario, que deja sin protección a una parte importante de la población y que abre las puertas a un modelo dividido entre seguros privados, atención pública y la beneficencia. Se fragmenta así uno de los ejes básicos que aseguran la cohesión social y, más específicamente, la igualdad en términos de esperanza de vida libre de enfermedad y con calidad de vida.

La política de recortes también afecta al débil e incipiente sistema de atención a la dependencia, mediante la reducción de las prestaciones (ya de por sí escasas y poco desarrolladas), el establecimiento de tasas y otros conceptos (como por ejemplo, para la valoración), o la disminución de la cobertura de los servicios adjudicados. Estas medidas, que suponen un claro desmantelamiento del sistema, significan una importante pérdida de empleo, con una doble incidencia: por la vía de los recursos de las personas y los servicios que se prestan; y por la vía de los recursos del Estado que se pierden (bien porque deba hacerse cargo de la prestación por desempleo, bien porque deja de ingresar el IRPF).

Entre los distintos recortes, en el ámbito de la atención a las situaciones de dependencia, se pueden destacar los siguientes: se introducen sistemas de copago excepto para las rentas muy bajas; se suspende la incorporación de las personas en situación de dependencia moderada hasta el año 2015; se reduce la cuantía de las prestaciones por cuidados en el entorno familiar un $15 \%$, ahondándose de esta manera las situaciones económicas vulnerables, tanto de las personas dependientes como de sus entornos familiares; y se deja de cotizar a la Seguridad Social por los cuidadores no profesionales. Con la reforma, ellos mismos han de hacerse cargo de tal cotización. Esta medida afecta especialmente a las mujeres y sus derechos, ya que representan buena parte de las personas cuidadoras de los entornos familiares.

Todas estas medidas, como las adoptadas en el ámbito de la educación y la sanidad, suponen pasos decididos hacia el desmantelamiento de lo que ha sido llamado Estado del bienestar, ampliando la desprotección social, la desigualdad, la pobreza y el conflicto social.

\section{Conclusiones}

El Estado social, o su referente de Estado de bienestar en el entorno europeo, como marco general de convivencia, ya no es capaz de asegurar que el empleo -el trabajo retribuido- evite las situaciones de pobreza. La pobreza de la población se ha intensificado hasta tal punto que está afectando cada vez más a las personas integradas en el mercado de trabajo. La precarización de las condiciones de trabajo, los procesos de desprotección en el mercado de trabajo y el debilitamiento de los recursos sociales del Estado de bienestar están provocando un empobrecimiento creciente de la población: el $27 \%$ de la población en España se encuentra en riesgo de pobreza y exclusión social, y más del $12 \%$ de la población trabajadora vive por debajo del umbral de la pobreza.

El mayor empobrecimiento de los trabajadores y trabajadoras en España está vinculado con las características de un modelo productivo poco diversificado y centrado en actividades de escaso valor añadido; de un mercado de trabajo muy segmentado; un modelo de protección social débil y un sistema fiscal desequilibrado, configurados en el periodo de fuerte crecimiento económico vivido hasta el año 2007. De hecho, esta tendencia no fue capaz de reducir las tasas de pobreza por debajo de la media europea, y ha configurado un modelo muy vulnerable a los cambios de ciclo, como están demostrando los efectos económicos y sociales de la actual crisis.

Esto explica no sólo la gravedad del proceso de empobrecimiento, sino también de determinados factores que inciden en la heterogeneidad de esta realidad, ligada a las situaciones de precariedad laboral y socioeconómica, que afecta especialmente a perfiles personales específicos relacionados con el sexo, la edad o la nacionalidad, y determinados por los contextos familiares de acceso al empleo, número de miembros en condiciones de dependencia económica o situaciones de privación material y social.

La crisis económica ha agudizado la pobreza de las personas con empleo, con diferente impacto en función de las desigualdades laborales previamente existentes. Además de las alarmantes cifras de desempleo, como consecuencia de la crisis (y amparándose en ésta), se está produciendo una fuerte presión a la baja de las condiciones laborales de la población trabajadora. La fuerte precariedad del empleo, la reducción de los salarios o la prolongación de la jornada de trabajo son algunos de los elementos que ponen de relieve esta tendencia.

A ello se añaden los cambios que se están produciendo en el marco de relaciones laborales de España, 
que modifican sustancialmente las relaciones de poder y los ámbitos y capacidad de la negociación colectiva, (dando más poder al empresariado), y con ello, obstaculizan la capacidad de asegurar la calidad de trabajo y de vida de las personas. En España este tipo de medidas laborales se han visto acompañadas de otras tantas de reducción de los marcos de protección social y de contracción de los servicios públicos; reducciones que están contribuyendo a que el fenómeno de los trabajadores pobres se haya incrementado de una manera muy acusada, mientras que los niveles de desigualdad crecen considerablemente.

Las consecuencias de estas medidas ya se están haciendo palpables, mientras la cobertura social se adelgaza. El aumento de las situaciones de pobreza y exclusión social implica un incremento de la demanda de servicios sociales, que sin embargo, se están viendo seriamente afectados por los recortes. La sanidad, la educación, la atención a la dependencia, pilares básicos del Estado de bienestar, ya han sufrido importantes recortes que afectan directamente a las condiciones de vida y trabajo de las personas, aseguran la igualdad de oportunidades y son los principales garantes de la cohesión social. Las consecuencias de la quiebra de estos principios acarrean consecuencias sociales y económicas de gran calado. Una parte importante de éstas es irreversible: la malnutrición infantil, la insalubridad de las condiciones de vida, la reducción de la atención y cuidado de la salud, la atención descualificada a las personas en situación de dependencia, la deprivación cultural, son sólo algunas de ellas.

Las pensiones y las prestaciones por desempleo han supuesto en España una de las claves para contener las situaciones de pobreza de las personas en los márgenes del mercado de trabajo y sus familias. Los límites para el acceso a los derechos de cobertura por desempleo, así como el incremento del gasto familiar por prestaciones sociales ya no cubiertas (en materia educativa o sanitaria), merman la capacidad de supervivencia de las más de 5,5 millones de personas en situación de desempleo y de los 1,7 millones de hogares con todos sus miembros activos en paro. A esta dramática situación, se suma la previsión de importantes recortes tanto en la cobertura por desempleo como en el sistema de pensiones, cuyas consecuencias pueden incrementar gravemente las situaciones de pobreza en los hogares.

Las barreras económicas para el acceso a una educación de calidad tienen importantes consecuencias para los hogares y el futuro del país. Las reformas educativas atentan directamente contra la calidad y el acceso a un servicio público clave para asegurar la igualdad de oportunidades. El aumento de las tasas en la educación superior sienta las bases de un sistema educativo elitista y semiprivatizado, que deja fuera a las personas de hogares con menos recursos y coarta la autonomía universitaria para la investigación y reflexión en campos que podrían ser fundamentales para un cambio de modelo productivo y social más sostenible, igualitario y libre.
La calidad de los servicios públicos está en juego: el descrédito de la función pública, el empeoramiento de las condiciones laborales y salariales de quienes trabajan en ella, y los incesantes recortes en prestaciones dan prueba de ello. Las diversas medidas que se están llevando a cabo en los últimos años están suponiendo pasos firmes hacia el desmantelamiento del sector público, y la mercantilización total o parcial de gran parte de los servicios asociados a él, lo que los hará inaccesibles para los grupos sociales más vulnerables, profundizando así en la situación de riesgo de pobreza.

Los diferentes recortes implicarán la vuelta de las mujeres a las labores de cuidado en el hogar. El coste de oportunidad de participar en un mercado de trabajo especialmente precarizado para ellas: el incremento de las tasas educativas, la supresión de la educación infantil pública, así como de las becas de comedor, los recortes en la atención a la dependencia, el incremento de la carga de trabajo reproductivo para compensar los bajos ingresos salariales, o la posible regulación restrictiva en materia de interrupción voluntaria del embarazo, dibujan un panorama que parece llamar a una reducción de la participación de las mujeres en el mercado laboral regularizado.

A la altísima tasa de desempleo, se añaden el fuerte endeudamiento de las familias y las medidas impositivas regresivas. Unas de las consecuencias más visibles de la injusticia social y el empobrecimiento está relacionada con el acceso a la vivienda, que tras el boom inmobiliario ha dibujado un panorama desalentador de sobreendeudamiento, incapacidad de responder a los compromisos hipotecarios y desahucios continuos de familias que no dan por terminadas esas obligaciones económicas sobrevaloradas. Mientras, el mantenimiento y refuerzo de un sistema de recaudación fiscal ineficiente e injusto no hace sino empeorar la situación, con las reducciones en los gravámenes de sociedades, patrimonio o donaciones y sucesiones, a lo que se suman las recientes medidas de amnistía fiscal. Esta situación no sólo agrava la inequidad social, sino que implica una contracción del consumo y, con ello, una prolongación de la recesión económica.

Las perspectivas de aumento del paro, de descenso de las rentas de los hogares para los próximos años, así como las previsibles nuevas políticas de recortes, supondrán un empobrecimiento general de la población española y un descenso sustancial de la calidad de sus condiciones de vida. Los datos existentes hasta la fecha permiten apuntar que al finalizar 2012 es previsible que se haya alcanzado una tasa de pobreza cercana al $28 \%$, y cabe predecir que, con los nuevos e importantes recortes sociales, el ritmo de aumento de la pobreza se acelere significativamente en los próximos años.

El escenario de crisis económica está siendo aprovechado para realizar un profundo cambio del modelo social. El recorte presupuestario, el aumento de los impuestos, la reforma laboral y la drástica reduc- 
ción del gasto social suponen una remodelación del Estado de bienestar, si no su propio desmantelamiento. La política de recortes no es otra cosa sino un cambio sustancial del modelo de intervención del Estado, un impulso ideológico que se dirige hacia la protección individual del riesgo y la cobertura de las necesidades a través de la iniciativa privada.

El trabajo decente o de calidad parece haberse convertido en un lujo para quien lo mantiene y una quimera irreivindicable para quien quiera acceder a él. Es necesario romper con esta situación: es imprescindible una voluntad política firme para convertir el trabajo decente en una apuesta de futuro. No se trata tan sólo de potenciar una economía capaz de crear puestos de trabajo, sino de que sean puestos de trabajo de calidad, que garanticen los derechos de los trabajadores y trabajadoras, que se extienda la protección social y que promueva el diálogo social. El empleo de calidad es clave para generar un modelo económico sostenible con una salida más justa e igualitaria de la crisis, centrado en las condiciones de vida de las personas y capaz de mantener la cohesión social. 


\section{Referencias bibliográficas}

ESPAÑA (2012): “Real Decreto-ley 16/2012, de 20 de abril, de Medidas Urgentes para Garantizar la Sostenibilidad del Sistema Nacional de Salud y Mejorar la Calidad y Seguridad de sus Prestaciones", Boletín Oficial del Estado, no 98, 24-4-2012, págs. 31.278-31.312 [rhttp:// www.boe.es/boe/dias/2012/04/24/pdfs/ BOE-A-2012-5403.pdf)].

- (2012): “Real Decreto-ley 14/2012, de 20 de abril, de Medidas Urgentes de Racionalización del Gasto Público en el Ámbito Educativo", Boletín Oficial del Estado, nㅜ 96, 21-4-2012, págs. 30.977-30.984 [<http://www.boe.es/boe/ dias/2012/04/21/pdfs/BOE-A-2012-5337.pdf)].

- (2012): "Real Decreto-ley 3/2012, de 10 de febrero, de Medidas Urgentes para la Reforma del Mercado Laboral”, Boletín Oficial del Estado, no $36,11-2012$, págs. 12.483-12.546 [ [sttp:// www.boe.es/boe/dias/2011/06/11/pdfs/ BOE-A-2011-10131.pdf〉].

- (2011): “Real Decreto-ley 7/2011, de 10 de junio, de Medidas Urgentes para la Reforma de la Negociación Colectiva, Boletín Oficial del Estado, n- 139, 11-6-2011, págs. 60.070-60.087 [rhttp://www.boe.es/boe/dias/2011/06/11/ pdfs/BOE-A-2011-10131.pdf)].

- (2010): “Ley 35/2010, de 17 de septiembre, de Medidas Urgentes para la Reforma del Mercado de Trabajo", Boletín Oficial del Estado, nㅡ 227, 18-9-2010, págs. 79.278-79.326 [ [http:// www.boe.es/boe/dias/2010/09/18/pdfs/ BOE-A-2010-14301.pdf>].

EUROFOUND (2010): Working Poor in Europe, Dublín, Eurofound.
FUNDACIÓN DE LAS CAJAS DE AHORROS (2012): Panel de previsiones de la economía española, Madrid, Fundación de las Cajas de Ahorros [<http:// www.funcas.es/Indicadores/Indicadores. aspx?file $=4$ '].

GARCÍA-ESPEJO, I.; y GUTIÉRREZ, R. (2011): “Spain: Persisting inequalities in a growing employment context”, en FRASER, N.; GUTIÉRREZ, R.; y PEÑA-CASAS, R. Working Poverty in Europe. A Comparative Approach, Londres, Palgrave MacMillan.

GOERNE, A. (2011): "A comparative analysis of in-work poverty in the European Union", en FRASER, N.; GUTIÉRREZ, R.; y PEÑA-CASAS, R. Working Poverty in Europe. A Comparative Approach, Londres, Palgrave MacMillan.

RODRÍGUEZ CABRERO, G. (2010): In-work Poverty and Labour Market Segmentation. A study of National Policies, Bruselas, Comisión Europea.

LÓPEZ PELÁEZ, A. (2005): “Excluidos pero trabajadores: el círculo viciosos de los "trabajadores con bajo salario' en España”, Cuaderno de Relaciones Laborales, vol. 1, nํ-23, págs. 153-174 [<http:// revistas.ucm.es/index.php/CRLA/article/view/ CRLA0505110153A/32353'].

ROCHA, F.; ARAGÓN, J.; y CRUCES, J. (2008): Cambios productivos y empleo en España, Madrid, Ministerio de Trabajo e Inmigración.

SÁNCHEZ LLOPIS, E. (2010): El gasto social en España, serie Estudios de la Fundación, nº 30, Madrid, Fundación $1^{0}$ de Mayo.

VV.AA. (2012): Trabajadores pobres y empobrecimiento en España, Madrid, Fundación 1ํำ de Mayo. 